\begin{tabular}{|c|l|}
\hline Title & Preparation of decahedral anatase titania particles with high-level photocatalytic activity \\
\hline Author(s) & Sugishita, Noriyuki; Kuroda, Y asushi; Ohtani, Bunsho \\
\hline Citation & $\begin{array}{l}\text { Catalysis Today, 16411), 391-394 } \\
\text { https://doi.org/10.1016j.cattod.2010.11.003 }\end{array}$ \\
\hline Issue Date & 2011-04.30 \\
\hline Doc URL & http://hdl.handle.net/2115/47048 \\
\hline Type & article(author version) \\
\hline File Information & CT1641_391-394.pdf \\
\hline
\end{tabular}

Instructions for use 


\title{
Preparation of Decahedral Anatase Titania Particles with High-Level Photocatalytic Activity
}

Noriyuki SUGISHITA, ${ }^{\mathrm{a}^{*}}$ Yasushi KURODA, ${ }^{\mathrm{a}}$ and Bunsho OHTANI ${ }^{\mathrm{c}}$

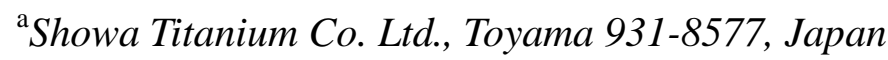

${ }^{\mathrm{c}}$ Catalysis Research Center, Hokkaido University, Sapporo 001-0021, Japan

\begin{abstract}
Anatase titania $\left(\mathrm{TiO}_{2}\right)$ particles were synthesized from titanium(IV) chloride $\left(\mathrm{TiCl}_{4}\right)$ and oxygen $\left(\mathrm{O}_{2}\right)$ through an improved gas-phase reaction process under rapid heating and rapid quenching conditions. The obtained particles were decahedral-shaped highly crystalline particles with specific surface area of $5-40 \mathrm{~m}^{2} \mathrm{~g}^{-1}$. These particles exhibited a level of photocatalytic activity higher than the representative commercial $\mathrm{TiO}_{2}$ photocatalysts for oxidative decomposition of acetic acid in an aqueous solution and acetaldehyde in air. Their higher level of activity is considered to be due to a combination of their moderate specific surface area and high crystallinity.
\end{abstract}

\section{Keywords}

photocatalyst; decahedral particles; anatase.

${ }^{*}$ Corresponding author.

Tel: +81-76-437-9201; fax: +81-76-437-6600

E-mail address: Noriyuki_Sugishita@sdk.co.jp 


\section{Introduction}

It has been reported recently that decahedral-shaped anatase $\mathrm{TiO}_{2}$ particles have been prepared from $\mathrm{TiCl}_{4}$ and $\mathrm{O}_{2}$ through a gas-phase reaction using a hydrogen-oxygen flame burner as the heat source, and have exhibited a high level of photocatalytic activity $[1,2]$.

It has been reported also that a liquid-phase reaction process added to the above gas-phase reaction produces decahedral $\mathrm{TiO}_{2}$ particles [3], but the mean particle size of those produced by this latter method is larger than $1 \mu \mathrm{m}$. Furthermore, the liquid-phase reaction process is a hydrothermal reaction of titanium (IV) fluoride $\left(\mathrm{TiF}_{4}\right)$ with hydrofluoric acid and seems not suitable for industrial production. In this study, the former gas-phase reaction which is applicable to industrial processes was improved, precise control of the reaction conditions was achieved, and attempts were made to enhance their photocatalytic activity.

\section{Experimental}

\subsection{Methods for synthesis}

An infrared furnace (ULVAC-Riko) was used as a heating instrument (Fig. 1) [4]. A quartz reactor tube was placed in the infrared furnace. A portion of the quartz reactor tube was wrapped with a platinum foil and this portion only was heated. The temperature of the platinum foil was set at $1200^{\circ} \mathrm{C}$. Mixed gas of $\mathrm{TiCl}_{4}$ and $\mathrm{O}_{2}$ preheated to a fixed temperature was introduced into the quartz reactor tube, passed through the heating zone and then quenched rapidly.

\subsection{Photocatalytic decomposition of acetic acid (AcOH) in an aqueous solution}

A 5.0vol\% aqueous $\mathrm{AcOH}$ solution $(5.0 \mathrm{~mL})$ and $\mathrm{TiO}_{2}$ powder $(50 \mathrm{mg})$ were put in a test tube which was then sealed off with a rubber septum and irradiated with the light of a high-pressure mercury lamp under vigorous stirring. The amount of carbon dioxide $\left(\mathrm{CO}_{2}\right)$ produced was measured by using a TCD gas chromatograph (GC) (Shimadzu GC-8A).

\subsection{Photocatalytic decomposition of acetaldehyde in air (Fig. 4, 7)}

$\mathrm{TiO}_{2}$ powder $(10 \mathrm{mg})$ was dispersed in water in a glass dish of $27-\mathrm{mm}$ inner diameter 
and dried at $110^{\circ} \mathrm{C}$. The glass dish was placed in a glass chamber of $500 \mathrm{~mL}$ volume. Acetaldehyde (500 ppm) and water (5.8 $\mu \mathrm{L}$, corresponding to $50 \% \mathrm{RH}$ at $\left.25^{\circ} \mathrm{C}\right)$ were injected into the chamber, which was then irradiated with light at the intensity of $0.2 \mathrm{~mW} \mathrm{~cm}^{-2}$ from a xenon lamp. The amount of $\mathrm{CO}_{2}$ produced was measured by TCD-GC.

\section{Results and Discussion}

\subsection{Improvement of the apparatus for synthesis}

The previously reported method for synthesizing decahedral $\mathrm{TiO}_{2}$ particles by a gas-phase reaction using a hydrogen-oxygen flame burner heated the raw material gas locally from the outside of the reactor tube. Since the temperature of the burner was controlled by the mixing ratio of oxygen and hydrogen, it was difficult to regulate the temperature of the heating zone precisely.

On the other hand, the apparatus used in the present study had a heating system in which only a platinum foil is heated by absorption of the infrared light irradiated from an infrared furnace. Accordingly, the part of the reactor tube which is in contact with the platinum foil is heated locally. In addition, as shown in Fig. 1, a thermocouple was set on the platinum foil and the intensity of an infrared light was controlled by a temperature controller so as to regulate the temperature on the platinum plate itself to a given temperature. Thus, the heating zone and the heating temperature of the reactor could be controlled precisely by a combination of platinum foil and an infrared furnace. This apparatus is suitable for realizing the rapid heating and rapid quenching conditions suited to synthesis of the decahedral-shaped particles.

Additionally, a baffle was set in the inside of the quartz reactor tube to make the raw material gas pass near the platinum foil where the highest temperature would be attained. By installing this baffle, the yield of the decahedral-shaped particles was increased and the uniformity of particle size was also improved. It is considered that these improvements were achieved by facilitation of generation of homogeneous cores due to uniform heating of the raw material gas in the heating zone. Figure 2 shows SEM images of the decahedral-shaped 
anatase $\mathrm{TiO}_{2}$ particles (Particles $A$ ) with specific surface area of $25 \mathrm{~m}^{2} \mathrm{~g}^{-1}$ prepared with the apparatus shown in Fig. 1. These results indicate that the decahedral-shaped anatase particles can be prepared by using either a burner or an electric furnace in a gas-phase reaction process comprising rapid heating and rapid quenching of the raw materials. 


\subsection{Photocatalytic activity of decahedral anatase $\mathrm{TiO}_{2}$ particles}

Figure 3 shows the relationship between the acetic-acid decomposition activity in a liquid-phase and the specific surface area of the decahedral particles prepared with the use of an apparatus indicated in Fig. 1. Generally photocatalytic $\mathrm{TiO}_{2}$ particles with the larger specific surface area tend to have the higher activity, because the larger surface area facilitates more adsorption of a reaction substrate [5]. Similarly, there was a trend toward higher activity in the decahedral anatase $\mathrm{TiO}_{2}$ particles with the larger specific surface area with the highest activity being 2 times higher than that of P25 (Nippon Aerosil; $40 \mathrm{~m}^{2} \mathrm{~g}^{-1}$ ).

On the other hand, there is a local maximum of photocatalytic activity at around 12 $\mathrm{m}^{2} / \mathrm{g}$ of surface area in figure 3 . The activity at this local maximum does not differ so much from that at $50 \mathrm{~m}^{2} / \mathrm{g}$. Surface area is one possible factor to affect photocatalytic activity, but it's not the only factor. The specific surface area of the particles was controlled by varying concentration of $\mathrm{TiCl}_{4}$ in the feed gas. And the concentration of $\mathrm{TiCl}_{4}$ was controlled by varying the volume of the raw material gas $\left(\mathrm{Ar}\right.$ and $\left.\mathrm{O}_{2}\right)$. Thus in addition to the concentration of $\mathrm{TiCl}_{4}$, the time during when the reaction gas stayed at the main heating zone were also changed. The difference of the staying time may have changed another variable factor (e.g. crystal structure) to affect photocatalytic activity.

High photocatalytic activity of the decahedral-shaped anatase $\mathrm{TiO}_{2}$ particles was also observed in decomposition of acetaldehyde in a gas-phase. In Fig. 4 are shown the results of evaluation of the activity of photocatalytic anatase $\mathrm{TiO}_{2}$ particles prepared by industrialized gas-phase processes and that of Particles A. Both particles had sufficient activity to decompose 500 ppm of acetaldehyde entirely. Rate of $\mathrm{CO}_{2}$ liberation by Particles $A$ was 1.8 times higher than that by P25 and 1.5 times higher than that by FP-6 (Showa Titanium; $\left.100 \mathrm{~m}^{2} \mathrm{~g}^{-1}\right)$.

\subsection{Discussion on activity of decahedral anatase $\mathrm{TiO}_{2}$ particles}

The XRD pattern of each particle, shown in Fig. 5, indicates that Particles A and FP-6 primarily consist of an anatase crystal-phase.

By comparing the SEM image of Particles A (with a $70 \mathrm{~nm}$ mean primary particle size) 
shown in Fig. 2 and that of FP-6 (with a $15 \mathrm{~nm}$ mean primary particle size) provided in Fig. 6, the difference in specific surface areas between these 2 types of particles are visually understandable. Particles $A$ have a higher activity than those of active commercial titania products, even though it have a crystal-phase comparable to those of the latter but noticeably smaller specific surface area than those of the latter. Those results suggest that decahedral $\mathrm{TiO}_{2}$ particles have high potential as a material for photocatalysts.

This suggestion can be deduced also from the relationship between specific surface area of particles and their acetaldehyde decomposition activity in a gas-phase, as shown in Fig. 7.

\section{Conclusions}

Highly active decahedral anatase titania particles were fabricated with high reproducibility and efficiency through a gas-phase reaction process with improved heating by an infrared furnace that allowed precise control of heating temperature, residence time and other conditions.

In assessments in a liquid-phase and a gas-phase, the decahedral anatase titania particles that were prepared with this improved apparatus were found to have high activity. Since decahedral particles with 70-nm primary particle size were found to have higher activity than those of FP-6 with 15 nm primary particle size, it suggests that decahedral particles have high potential as a material for photocatalysts. After this study, we have started to establish techniques for mass production of the decahedral anatase titania particles.

\section{Acknowledgements}

This study was partly supported by the "Project to Create Photocatalyst Industry for Recycling-Oriented Society" supported by the New Energy and Industrial Technology Development Organization (NEDO).

\section{References}

[1] F. Amano, O. O. Prieto-Mahaney, Y. Terada, T. Yasumoto, T. Shibayama, B. Ohtani, 
Chem. Mater. 21 (2009) 2601.

[2] B. Ohtani, F. Amano, T. Yasumoto, O.O. Prieto-Mahaney, S. Uchida, T. Shibayama and Y. Terada Top. Catal. 53 (2010) 455.

[3] H. G.. Yang, C. H. Sun, S. Z. Qiao, J. Zou, G. Liu, S. S. Smith, H. M. Cheng, G. Q. Lu, Nature 453 (2008) 638.

[4] N. Sugishita, Y. Kuroda, B. Ohtani, Abstracts for The 15th Symposium "Recent Developments on Photocatalysis", December 2, 2008, Kanagawa, pp. 64-65.

[5] O.O. Prieto-Mahaney, N. Murakami, R. Abe and B. Ohtani Chem. Lett. 38 (2009) 238.

\section{Figure Captions}

Fig. 1 Gas-phase reaction apparatus for the preparation of decahedral anatase titania particles.

Fig. 2 SEM image of decahedral anatase titania particles prepared through gas-phase process, Particles A (ca 70-nm primary particle size and $25-\mathrm{m}^{2} \mathrm{~g}^{-1}$ specific surface area).

Fig. 3 Relationship between specific surface area and photocatalytic $\mathrm{CO}_{2}$ production from an aqueous solution of 5vol\% acetic acid. Circles: decahedral anatase titania particles. Triangle: P25.

Fig. 4 Photocatalytic activity for mineralization of acetaldehyde in air.

Fig. 5 XRD patterns of titania samples. Baselines were shifted for clarity.

Fig. 6 SEM image of FP-6 (Showa Titanium; ca 15-nm primary particle size and $100 \mathrm{~m}^{2} \mathrm{~g}^{-1}$ specific surface area).

Fig. 7 Relationship between specific surface area and photocatalytic activity for mineralization of acetaldehyde in air. 


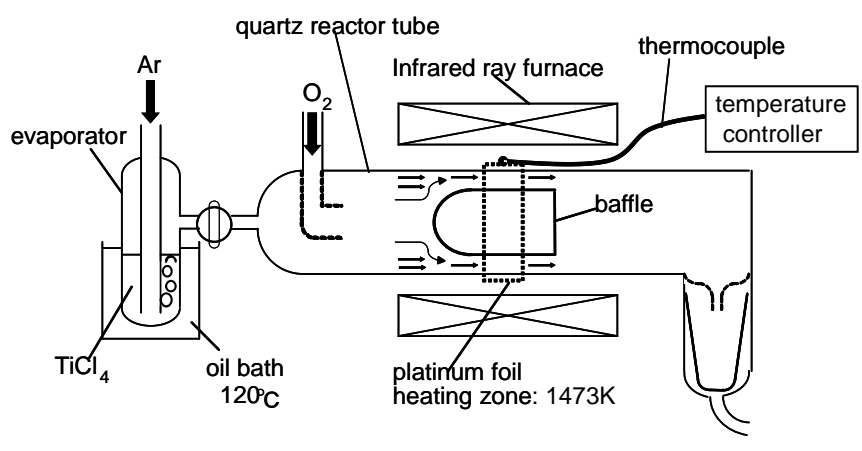

Figure 1 


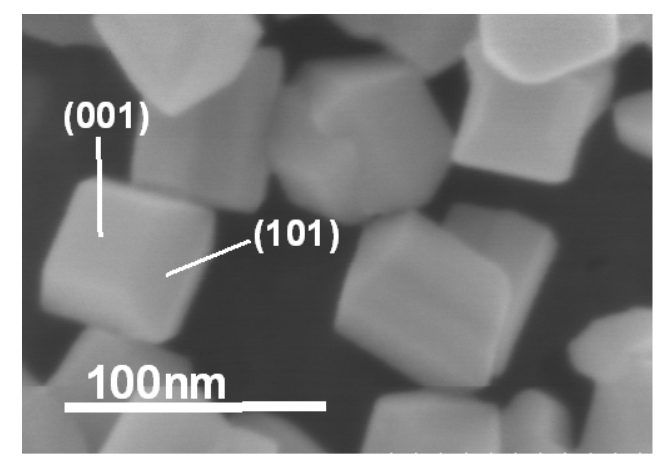

Figure 2 


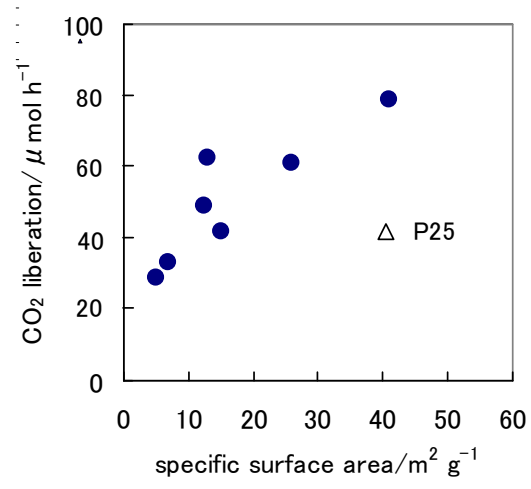

Figure 3 

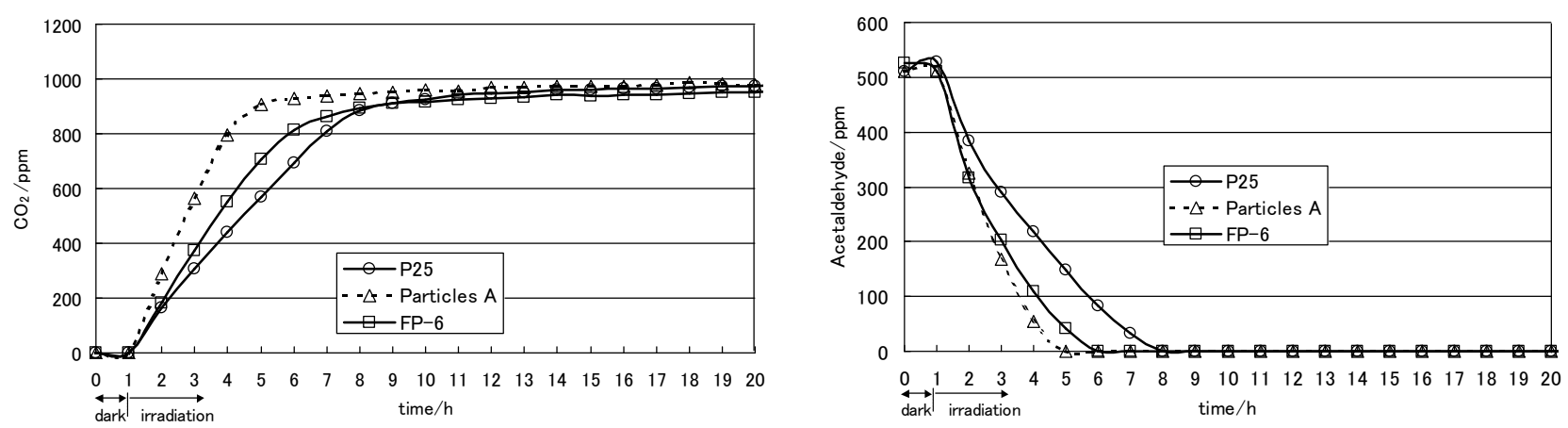

Figure 4 


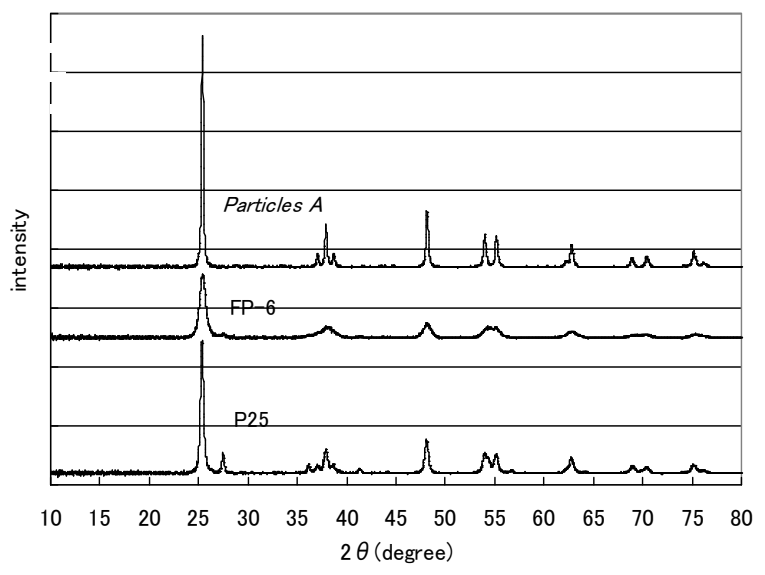

Figure 5 


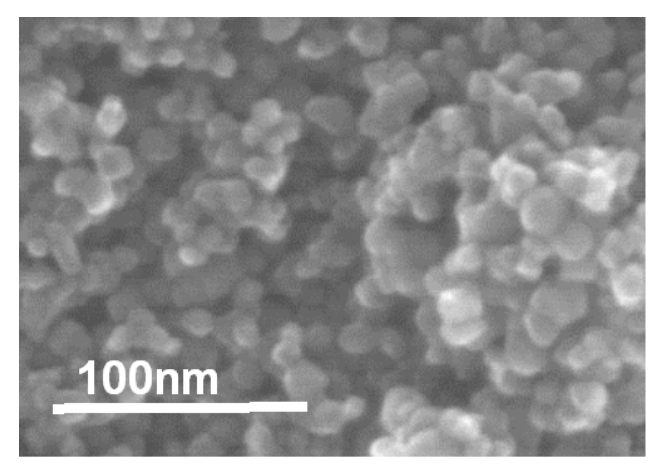

Figure 6 


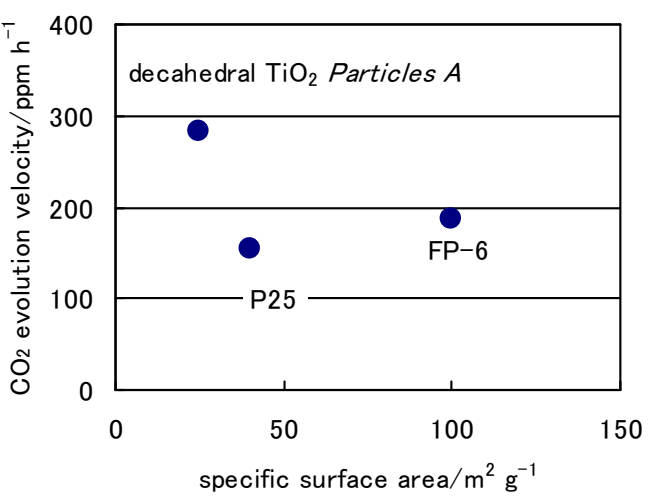

Figure 7 